\title{
Adaptation of assistive and robotic technology to teach music to deaf children.
}

\author{
Cristiano da Silva Benites ${ }^{1}$, Ismar Frango Silveira ${ }^{1}$, \\ ${ }^{1}$ Faculdade de Computação e Informatica, \\ Universidade Presbiteriana Mackenzie - São Paulo, SP - Brazil \\ benites_silva@hotmail.com, ismarfrango@gmail.com
}

\begin{abstract}
This research reports challenges that are found in the inclusion of children with hearing impairment in music learning and presents how society accepts these individuals. It seeks to know how the deaf community sees music and finally to evaluate visual and technological elements in children's musical education. The challenges of the presented actions do not aim at a theory of comprehensive form or only statistical, but it seeks to propose a succinct discussion on the theme, to bring the other people to a reflection regarding the specific needs of these children.
\end{abstract}

Resumo. Esta pesquisa relata desafios encontrados na inclusão de crianças com deficiência auditiva no aprendizado de música e apresenta como a sociedade aceita esses indivíduos. Busca conhecer como a comunidade de surdos vê a música e, finalmente, avaliar elementos visuais e tecnológicos na educação musical infantil. Os desafios das ações apresentadas não visam uma teoria de forma abrangente ou apenas estatística, mas buscam propor uma discussão sucinta sobre o tema, para levar as outras pessoas a uma reflexão sobre as necessidades específicas dessas crianças.

\section{Introdução.}

A relação entre surdez e música é um assunto polêmico desde o passado até os dias de hoje, já que a música é considerada um fenômeno do meio audível e o surdo não consegue ouvir o som, mas pode senti-lo pelas vibrações no próprio corpo. As pessoas que defendem a cultura dos surdos afirmam que a música é criada e entendida para concepção dos indivíduos ouvintes, como consequência não faz parte da cultura surda, então os surdos não podem desfrutar da música do mesmo modo igual fazem os ouvintes [Glennie, 2018].

Dessa forma, para o autor [Finck, 2009], o processo de escutar é relacionado à percepção dos sentidos e não somente à audição, então se a música é uma expressão em forma de sons, como o indivíduo surdo pode perceber música? Nesta parte é notória a necessidade de serem criadas propostas pedagógicas para o ensino de música para pessoas surdas. É interessante destacar que os surdos sentem vibrações por meio da pele: esse evento ocorre no surdo por um local no cérebro que é o mesmo local do ouvinte, assim esse local lhes dá uma percepção diferente da forma de compreender a leitura do ritmo musical, uma abordagem não tão comum, mas que pode ser usada por 
VIII Congresso Brasileiro de Informática na Educação (CBIE 2019)

Anais do XXV Workshop de Informática na Escola (WIE 2019)

meio da sensibilidade tátil, que lhes permitem obter percepções das vibrações sonoras, que nada mais é a percepção vibrotátil.

Ondas de vibração, que são transmitidas por meio do ar, chegam até a pele, e assim são sentidas pelos músculos e ossos, atingindo por fim o sistema nervoso autônomo, permitindo assim sentir ritmo e volume, intensidade e duração do som [Haguiara-Cervellini, 2003]. Essas percepções, quando integradas à percepção do movimento interno, podem permitir que o surdo aprecie elementos do som [Benenzon, 1985]. O mesmo autor ainda apresenta uma relação do surdo com a música e propõe a substituição de seu sistema auditivo pelos recursos táteis, os quais permitiriam ao surdo ter consciência do som que o circula.

Ainda analisando estudos que utilizam perspectivas de vibrações sonoras, notase que elas não somente são percebidas por aparelhos auditivos. Assim, pode-se citar estudos clássicos como os de [Madsen, 1965], em que os mesmos mediram a sensibilidade tátil de pessoas com deficiência auditiva chegando a resultados satisfatórios. Um ano antes, [Gescheider, 1964] demonstrou a precisão com a qual a pele pode identificar as vibrações do som.

Quanto à sensibilidade de crianças com surdez em relação à música, [HaguiaraCervellini, 2003] comprovou que elas procuram percebê-la usando todo o corpo para sentir vibrações do chão, de paredes e também instrumentos musicais. Dessa forma, surdos geralmente apresentam preferência por instrumentos de percussão, que produzem vibrações fortes e são percebidos de forma mais fácil, segundo o mesmo autor. Nesse sentido, o surdo precisa ter todas as chances de vivência musical para poder desenvolver sua sensibilidade da música.

\section{As pessoas surdas em contato com a musica.}

Para muitos acadêmicos, a relação entre música e deficiência auditiva é considerada um paradoxo. De Acordo com [Mahler, 2016] os músicos e compositores geralmente são presumidos de terem uma "audição normal”, assim a autora gera uma argumentação cuja suposição leva estudiosos a imaginar a surdez como a mais profunda antítese no meio musical, o que os fazem considerar uma pessoa surda como incapaz para a música. Isso acaba promovendo a distância entre essas pessoas e a música, e consequentemente as distanciam dos benefícios que a música pode promover para o indivíduo.

Relatos de pessoas com surdez interessadas em música, permitem trazer uma reflexão sobre a relação dessas pessoas com a música e conhecer diferentes formas de experiência no contexto musical a partir das suas práticas [Mahler, 2016]. O autor ainda nos desafia a pensar a música que vai além dos nossos ouvidos, e imaginar modos alternativos que a música nos permite ter, viver a experiência que um surdo tem e dessa forma mostrar que os músicos surdos interagem com sons da sensação proporcionada pelas vibrações e uso de imagens. 
O primeiro registro de educação musical para uma pessoa surda foi citado por [Darrow, 2016] onde uma jovem surda desejava ter o aprendizado de piano. O artigo citado relatou a experiência do ensino musical para Augusta Avery of Syracuse. Assim, percebeu-se que a música pode ser ensinada para os surdos e ao mesmo tempo sentida, de forma que possam ter uma ideia do ritmo musical, qualidade de expressão e relação dos tons, formando o uso da visão e do toque.

Na atualidade a educação de música tem tido evolução no âmbito de inclusão do indivíduo surdo, as experiências que valorizam situações em que envolvem sensações vibráteis, expressão do corpo e a do relacionamento entre som e imagem, experiências que facilitam o uso de ferramentas tecnológicas.

\section{Trabalhos relacionados.}

Na última década foram realizados vários estudos e pesquisas visando criar novas tecnologias para ajudar as pessoas com surdez a sentir o prazer de ter contato com a música. Abaixo iremos abordar algumas ferramentas existentes que foram criadas a partir do ano de 2009.

Temos o “Touchingnotes II” desenvolvido no ano de 2011 tratando da música para os sentidos, e tem por finalidade interpretar os comandos que atuam no protocolo MIDI recebidos a partir de um teclado musical, assim reconhecendo as notas musicais pela vibração (na figura 1 é possível ter uma noção). A interpretação é realizada no dispositivo por notas recebidas do teclado musical, assim ele transforma a nota em frequências que são sentidas na pulseira no braço do usuário, que sente a vibração na pele. O dispositivo ainda possui controle de tom, podendo assim ser transpostas as oitavas das notas do teclado, além de controlar a intensidade, de forma que o seu ajuste seja compatível com a sensibilidade do usuário.

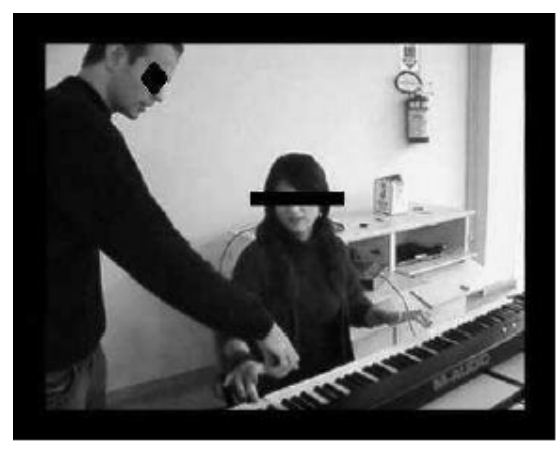

Figura 1: Touchingnotes II.

Como teste, o experimento contou com crianças surdas, onde o autor do projeto mostrou, de forma geral, que foi possível a criança sentir as vibrações na pulseira, e as mesma relataram ser uma atividade agradável e prazerosa. As crianças surdas perceberam a qualidade musical, na intensidade, harmonia e tonalidade. $\mathrm{O}$ dispositivo 
VIII Congresso Brasileiro de Informática na Educação (CBIE 2019)

Anais do XXV Workshop de Informática na Escola (WIE 2019)

pode ajudar a criança surda no aprendizado musical, e além do mais o projeto pode ser integrado a um software, para outra finalidade que não seja musical.

Desenvolvido em 2015 por Ortega Software "Cromo Tmusic", tem como objetivo principal auxiliar na musicoterapia com um in111strumento musical dos surdos, desenvolvendo atividades na percepção e cognição musical.

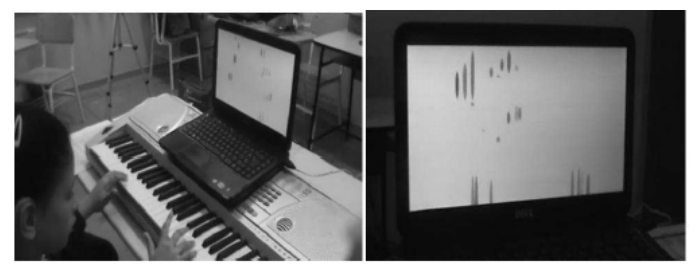

Figura 2: Cromo Tmusic.

O software possui duas janelas principais onde a tela inicial mostra as notas musicais, como sendo espelho do teclado tocado pela criança. A segunda tela exibe os diagramas formados quando o instrumento musical é tocado. Faz-se o uso de um teclado com entrada MIDI, onde o mesmo é conectado em um computador, gerando comunicação com o software, que faz a conversão das notas do instrumento em gráficos e diagramas, correlacionando ambos de forma simultânea.

A aplicação é voltada para crianças surdas, via computador, e a relevância do sistema é o fato de poder ser utilizado como instrumento musical para músicoterapeutas no tratamento de patologias diversas, como também na pedagogia auxiliando na percepção das crianças surdas.

O Ludwig é um projeto desenvolvido em 2015 para ser utilizado em dispositivos móveis que utilizam do sistema IOS (Apple) e é integrado a uma pulseira que fica no braço, como mostrado na figura 3. O sistema foi criado por alunos que fazem parte da Metrocamp de Campinas

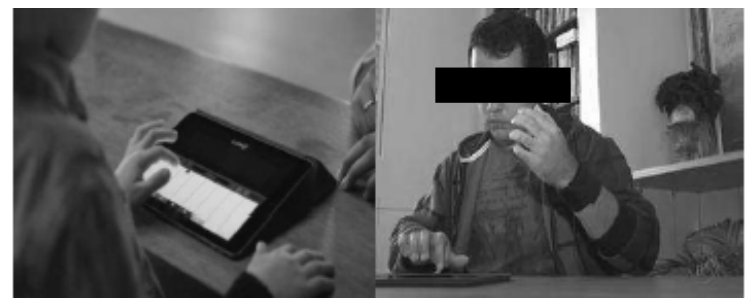

Figura 3: Ludwig.

O aplicativo foi destaque na WWDC "Worldwide Developers Conference" (Conferência de Desenvolvedores da Apple), em 2015 que ocorreu em San Francisco na Califórnia (EUA). O nome escolhido do aplicativo é uma homenagem a Ludwig van Beethoven. Ele ainda permite o uso dos outros sentidos como tato e visão o que chamou 
VIII Congresso Brasileiro de Informática na Educação (CBIE 2019)

Anais do XXV Workshop de Informática na Escola (WIE 2019)

a atenção de instituições de outros países, para assim trabalharem com os deficientes auditivos.

\section{Metodologia.}

Selecionamos um grupo com 7 crianças com idades entre 5 e 10 anos, para fazer uso de um processo musical utilizando robótica e softwares. Dentre essas crianças 6 são portadoras de deficiência auditiva e precisam de intérpretes para auxiliá-las. Em todo o processo houve consentimento de seus responsáveis. Na tabela 1 apresentamos a situação de comunicação de cada uma das 7 crianças que participaram do experimento, para saber a circunstância envolvida no experimento, assim na tabela inserimos o que nos foi relatado pelos responsáveis pelas crianças onde " $\boldsymbol{V}$ ” indica positivo e “-” indica negativo e o que foi comprovado durante os experimentos.

Tabela 1: Comunicação de cada criança.

\begin{tabular}{|c|c|c|c|c|c|}
\hline \multicolumn{5}{|c|}{ SITUAÇÃO DE COMUNICAÇÃO DE CADA CRIANÇA } \\
\hline PARTICIPANTTS & LEITURA & LIBRAS & \multicolumn{4}{c|}{ GRAU DE SURDEZ } \\
& & & MODERADA & SEVERA & PROFUNDA \\
\hline CRIANCA 1 & $\checkmark$ & - & - & - & - \\
\hline CRIANCSA 2 & - & - & - & - & $\checkmark$ \\
\hline CRIANÇA 3 & $\checkmark$ & - & - & - & $\checkmark$ \\
\hline CRIANCSA 4 & - & - & - & - & $\checkmark$ \\
\hline CRIANCSA 5 & - & - & - & - & $\checkmark$ \\
\hline CRIANCA 6 & - & - & - & - & $\checkmark$ \\
\hline CRIANCSA 7 & $\checkmark$ & $\checkmark$ & - & - & $\checkmark$ \\
\hline CRIANCSA 8 & $\checkmark$ & $\checkmark$ & - & - & $\checkmark$ \\
\hline
\end{tabular}

Foram apresentados para a criança surda fundamentos da música, como por exemplo notas musicais combinadas com cores para facilitar a identificação, ritmos e tempos dos compassos musicais representados pelo movimento de um robô. Saindo assim do modo tradicional que pode ser uso de livro, lousa ou qualquer outro meio que não seja com uso de tecnologia.

Antes de iniciar qualquer atividade com o robô e as crianças, iremos ensinar 0 conceito do projeto para que elas possam entender o que cada item quer dizer durante a prática do jogo, pois nenhuma das crianças têm conhecimento musical. Dessa forma iremos ensinar as cores das notas musicais como teoria proposta nessa atividade.

Assim que cada criança souber qual cor pertencente à nota musical, foi pedido a ela que apontasse no IPAD qual nota o robô estava indicando, podendo a criança apontar com o dedo na tela do dispositivo. Para isso foi utilizado no projeto o programa Editom, para que fosse possível utilizar o pentagrama e ser possível colorir as notas musicais de acordo com a necessidade do experimento. $\mathrm{O}$ software Editom foi criado para ensinar música para pessoas iniciantes, representando assim de forma gráfica forma de escrever música e ouvir os sons das notas. No experimento, o Editom será utilizado apenas para representação visual para as crianças surdas. 
Após as crianças terem base do que quer dizer cada cor no pentagrama, iremos passar para a segunda parte da teoria que diz respeito ao tempo rítmico, pode-se dentro do aplicativo fazer o uso dos tempos já definidos, dessa forma a criança apenas seleciona o movimento que quer para o robô.

Com o conteúdo conceitual embasado iremos começar a praticar cores com o robô. Cada nota musical que é tocada no piano digital no IPAD irá apresentar uma cor no robô, o LED colorido será combinado com um movimento do robô, assim a criança já irá começar a saber qual cor pertence a qual nota musical e seu tempo rítmico na prática, de acordo com a escolha rítmica. Quando a criança clicar na tecla vermelha o robô irá acender a luz vermelha, dessa forma a criança saberá que ela pressionou a nota DÓ no teclado virtual. O robô, além de acender a luz vermelha, irá vibrar para que a criança sinta que houve alguma ação no robô quando ela executou algum comando no IPAD.

Para que o robô possa executar e reconhecer os comandos enviados a partir do IPAD, foi preciso compilar os códigos dentro do Arduino do robô, assim utilizamos a linguagem de programação (mBlock) no modo Python que é uma linguagem de programação suportada pelo aplicativo. Com o uso dos jogos será possível saber qual foi a abstração dos conceitos que as crianças adquiriram com o experimento.

Para tornar simples a utilização da proposta prática, será criado um plano guia para os experimentos: no caso serão três planos, um para cada domingo de atividades. Nas três iremos fazer uso do robô e somente no último experimento teremos uma mudança, que será a inserção do piano de cauda e uma pulseira de vibração. Além disso contaremos com intérpretes para facilitar a comunicação com as crianças,

\section{Etapas realizadas dos experimentos pilotos.}

O primeiro contato com as crianças durou cerca de 4 horas, assim, fizemos a montagem do robô com as crianças, que durou mais ou menos 30 minutos, iniciamos a atividade. Nessa primeira etapa a criança ouvinte começou a fazer o primeiro contato com o robô e as outras crianças acompanhavam o que era feito, conforme apresenta a figura 4.

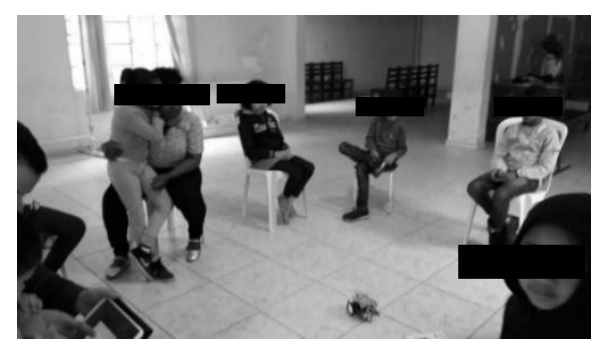

Fig. 4: Primeira criança fazendo a atividade. 
Ainda no primeiro dia de contato, quando uma criança terminava de realizar a atividade era a vez de outra criança assumir o posto e fazer o mesmo procedimento realizado pela criança anterior, assim elas acabaram fazendo a mesma atividade por sete vezes seguidas, para que dessa forma as cores e os movimentos pudessem ficar difundidos em suas mentes devido à repetição.

O segundo dia de contato, que foi um domingo após a primeira atividade, esperava-se que fosse preciso relembrar as crianças das cores das notas e dos tempos dos compassos que eram feitos os movimentos. Gerou-se uma surpresa com o fato das crianças ainda estarem com todo o referencial da primeira etapa em mente, lembravam de todas as cores das notas e do tempo de cada compasso. Dessa forma, como não foi preciso relembrar o que foi feito no domingo anterior até porque já estava previsto no plano da atividade da segunda etapa, fomos direto ao jogo para as crianças executarem o proposto. Iniciamos dessa vez pela criança surda mais nova, pois acreditava-se que ela estava com o conceito teórico em mente e poderia executar a atividade musical com pouca dificuldade.

Para a terceira etapa fizemos o uso do robô que já era usado desde a primeira etapa, mas diferentemente das outras ocasiões as crianças não comandariam o robô, utilizando o IPAD ou controle de comandos do mesmo, mas nessa etapa as crianças iriam utilizar o robô como referência para saber as notas que elas estavam pressionando na tecla do piano. Nas etapas anteriores as crianças estavam interagindo com o robô para sentir vibração e imitar os movimentos dele para assim ter uma noção do que poderiam sentir quando estivessem em contato com um piano de verdade, o que era planejado ocorrer nesta etapa final do projeto.

Para a realização da atividade final utilizamos um piano de cauda da Roland que estava na localidade dos experimentos, o modelo usado foi o "Gp607 Pel”, fizemos o uso do mesmo por um período de 5 horas. Esse piano possui entradas USB e P10, no caso a entrada USB do piano foi primordial nesse teste final, pois fizemos o uso da USB para integrar o robô ao piano e assim ajudar as crianças em sua compreensão. Dessa forma buscamos o paralelismo, para que quando fosse executada uma nota no piano o robô gerar uma cor e uma vibração no robô ao mesmo tempo.

Como nos dois primeiros experimentos as crianças não tiveram contato com o piano, isso poderia gerar uma dificuldade para elas, podendo gerar confusão, assim vimos que seria melhor inserir uma pulseira integrada ao robô. Dessa forma, quando as crianças tocassem uma nota musical no piano, o mesmo iria vibrar pelo fato de ser acústico, o robô teria que vibrar e acender o LED indicando a nota que foi tocada e pôr fim a pulseira estaria integrada ao robô gerando uma vibração no pulso da crianças.

Programamos o robô com antecedência com o intuito de chegar e apenas conectar o mesmo ao piano e já obtermos resposta satisfatória com as notas pressionadas no piano. Conectamos a entrada USB do robô ao piano, clicamos uma nota DÓ que era representada pela cor vermelha nos testes anteriores e assim como mostra a 
VIII Congresso Brasileiro de Informática na Educação (CBIE 2019)

Anais do XXV Workshop de Informática na Escola (WIE 2019)

imagem da figura 5 o robô ficou na cor vermelha como prevíamos, e assim também a pulseira vibrou com todas as notas musicais.

Ao executar a atividade final a criança ficava com a mão esquerda no piano e, por ser a mão com a pulseira, ela também sentia a vibração do piano e a vibração da pulseira. Tudo isso ocorria de forma sincronizada e buscava-se não ter atrasos, para não gerar confusão na cabeça das crianças durante sua participação no experimento.



Figura 5: Criança tocando piano com todos os recursos integrados.

No final do terceiro experimento, após todas as crianças participarem das atividades pode-se sentir a felicidade das mesmas, por terem sentido o prazer de ter o primeiro contato com a música de modo prático, algo que foi emocionante para as crianças e para todos os que estavam assistindo essa atividade com elas.

\section{Resultados e discussões.}

No momento em que as crianças com deficiência auditiva realizavam as atividades em cada um dos três experimentos, os orientadores avaliavam o desempenho de cada uma delas de acordo com as opções do questionário. Após o término dos três experimentos pilotos, foi possível ter um parecer do desempenho de cada criança que participou dos experimentos:

- Todas as crianças conseguiram realizar as atividades propostas usando o aplicativo via IPAD junto com o robô, fazendo todos os exercícios com êxito, além de terem gostado da atividade que gerou muita diversão entre elas em $100 \%$ dos casos.

-Nenhuma criança teve um treinamento específico ou separado das outras crianças para entender o conteúdo. Os orientadores avaliaram que cerca de $60 \%$ das crianças tinham que pensar um pouco mais para iniciar o processo, mas isso já era esperado, pois elas nunca tiveram contato com as tecnologias do experimento.

-100\% das crianças julgaram como fácil o entendimento das imagens para fazer a atividade, e também imitar o movimento do robô, julgou-se ser bem claro o processo pelos orientadores.

-Depois de semanas de atividades, $100 \%$ das crianças realizaram as atividades com o desempenho praticamente semelhantes nos três experimentos. 
As atividades realizadas nesta pesquisa indicaram que a junção da aplicação Scratch junto com um hardware, no caso deste trabalho um robô, podem proporcionar aprendizado de música para crianças deficientes auditivas. Assim, é fundamental se fazer uso de meios adaptativos na educação musical de crianças surdas, verificar a efetividade do aplicativo e hardware utilizado, estudar formas de saber qual o verdadeiro impacto causado em quem participa da do aprendizado, nesse caso as crianças deficientes auditivas.

\section{Considerações finais do projeto piloto.}

Assim que iniciamos as experiências da música com as crianças, foi possível analisar que a arquitetura utilizada com o aplicativo e o robô permitiram às crianças a realização da atividade musical, auxiliando na percepção dos sons que eram realizados com os compassos, vibração e ritmos por meio do robô. Após as crianças perceberem o som por meio da cor e movimento do robô,puderam produzir e se movimentar de acordo com a intensidade do mesmo, quando este gerava movimento e cores. Com isso era possível refletir sobre quais os benefícios que a música desempenhava nas crianças por meio de suas atitudes e os comentários dos orientadores no momento das atividades, pois estes estavam fazendo a avaliação das crianças enquanto elas realizavam as atividades, apresentando o conceito prático de que é possível e prazeroso ensinar música para crianças surdas.

Fazendo uso da avaliação dos orientadores das crianças, percebe-se no geral que eles indicaram que o uso da aplicação Scratch junto à robótica pode ser uma ótima forma para ser utilizada nas atividades musicais de crianças surdas. Mas foi possível notar que nem todas as crianças tiveram $100 \%$ um bom conceito no sentir da vibração do robô, o que apresentou que era preciso as crianças terem um treinamento háptico um pouco mais duradouro para assim poderem se acostumar com a vibração. O problema encontrado na questão da vibração estava no caso de o robô apenas vibrar ao receber uma nota quando ele estava no chão, a questão dos movimentos alguma vezes longo, colocou dificuldade para usá-lo numa mesa, que seria o ideal para a vibração, mas limitaria os movimentos do robô para as crianças o imitarem. Assim, o proposto inicial do projeto era trabalhar com as cores musicais e os tempos de compassos do robô, o que limitou o planejamento quanto à vibração e porque o robô era pequeno e tinha força de vibração limitada.

Dessa forma, esse trabalho deixa em evidência um estudo mais aprofundado da vibração casada com ensino de música para crianças surdas, principalmente no caso do tempo de vibração e de intensidades das notas musicais, para assim diferenciar as vibrações. Neste caso, focamos na diferenciação por meio das cores para não gerar confusão para as crianças. Foi feito uso de um dispositivo ligado ao braço da criança, uma espécie de relógio, assim quando o robô vibrava, a pulseira também vibrava na mesma intensidade de forma que o robô fosse responsável pelas cores e movimentos e a 
VIII Congresso Brasileiro de Informática na Educação (CBIE 2019)

Anais do XXV Workshop de Informática na Escola (WIE 2019)

pulseira pela vibração junto com o piano, conforme feito no último experimento.

Devemos considerar que ensinar música para crianças surdas tem que ter como propósito gerar reflexão no indivíduo, sobre como conceber a inclusão para pessoas com situações controversas às dos ouvintes, seja no ensinar da música ou comunicar-se com o outro através das libras ou também trazendo para o seu meio social a identidade real das crianças surdas, como consequência expandindo seu meio de vivências.

Espera-se que as lições aprendidas com a execução dessas experiências-piloto possam embasar a intervenção final sendo planejada para o término deste projeto.

\section{References}

Benenzon, R. (1985) “Manual de musicoterapia”. Rio de Janeiro: Ene livros.

Darrow, A. A., Heller, G. N. (1985) "Early Advocates of Music Education for the Hearing Impaired". William Wolcott Turner and David Ely Bartlett. Journal of Research in Music Education, Vol. 33, No. 4.

Finck, Regina (2009) "Ensinando Música ao Aluno Surdo: perspectiva para a ação pedagógica inclusiva”, tese de doutorado/UFRGS/Porto Alegre.

Gescheider, A. (1988) "Cutaneous sound localization. Journal of Experimental Psychology”. Washington, v70,n.6.

Glenie, (2018) The hearingessay, 2008. "We're seeking an additional Volinteer!", http://www.evelyn.co.uk/, Setembro.

Haguiara-Cervellini, N. (2003) "A musicalidade do surdo: representação e estigma”, São Paulo:Plexus.

Jones, J. D. (2016) "Imagined Hearing: Music-Making in Deaf Culture". New York: Oxford University Press.

Madsen, C. K, Mears, W. G. (1965) "The Effect of Sound Upon the Tactile Threshold of Deaf Subjects”. Journal of Music Therapy, 2(2), 64-68.

Mahler, A. (2016) "Musical Expression among Deaf and Hearing Song Signers". In: HOWE, B, JENSEN-MOULTON, S.; LERNER, N.; STRAUS, J. The Oxford Handbook of Music and Disability Studies. New York: Oxford University Press.

Montagu, A. (1988) “Tocar: o significado humano da pele”. Tradução de Maria Silva mourão Netto. São Paulo: Summus. 